Hydrology and Earth System Sciences, 4, 769-776 (1997) (C) EGS

\title{
Depth distribution of preferential flow patterns in a sandy loam soil as affected by tillage
}

\author{
C.T. Petersen*, S. Hansen, and H.E. Jensen \\ The Royal Veterinary and Agricultural University, Department of Agricultural Sciences, Laboratory of Agrohydrology and Bioclimatology, \\ Thorvaldsensvej 40, DK-1871 Frederiksberg C, Copenhagen, Denmark \\ * Corresponding author \\ Telephone: (+45) 35283389 \\ Telefax: (+45) 35283384 \\ E-mail: HEJ@KVL.DK
}

\begin{abstract}
Dye-tracer studies using the anionic dye Brilliant Blue FCF were conducted on a structured sandy loam soil (Typic Agrudalf). $25 \mathrm{~mm}$ of dye solution was applied to the surface of $111.6 \times 1.6 \mathrm{~m}$ field plots, some of which had been subjected to conventional seed bed preparation (harrowing) while others had been rotovated to either 5 or $15 \mathrm{~cm}$ depth before sowing. The soil was excavated to about $160 \mathrm{~cm}$ depth one or two days after dye application. Flow patterns and structural features appearing on vertical or horizontal cross sections were examined and photographed. The flow patterns were digitized, and depth functions for the number of activated flow pathways and the degree of dye coverage were calculated.

Dye was found below $100 \mathrm{~cm}$ depth on 26 out of 33 vertical cross sections made in conventionally tilled plots showing that preferential flow was a prevailing phenomenon. The depth-averaged number of stained flow pathways in the $25-100 \mathrm{~cm}$ layer was significantly smaller in a plot rotovated to $5 \mathrm{~cm}$ depth than in a conventionally tilled plot, both under relatively dry initial soil conditions and when the entire soil profiles were initially at field capacity. There were no examples of dye penetration below $25 \mathrm{~cm}$ depth one month after deep rotovation. Distinct horizontal structures in flow patterns appearing at 20-40 cm depth coupled with changes in flow domains indicated soil layering with abrupt changes in soil structure and hydraulic properties.
\end{abstract}

\section{Introduction}

Preferential flow phenomena can lead to rapid transport of water and surface-applied chemicals to deep subsoil layers, and may thereby increase the leaching losses of a broad variety of chemicals used in agriculture (e.g. Hall \& Mumma, 1994; Kladivko et al., 1991; Isensee et al., 1990; Hall $e$ al., 1989; see also reviews by Bouma, 1991; Jury \& Flühler, 1992; Flury, 1996). Tillage processes affect soil structure and hydraulic properties in the topsoil which are expected to be important for the generation of preferential flow (e.g. Beven and Germann, 1982; Horton et al., 1989; Staricka $e t$ al., 1991). Systematic effects of tillage on flow patterns and chemical transport are thus expected.

Direct quantification of preferential flow under field conditions, particularly of macropore flow, is very difficult, not only because of spatial variability but also because of the temporal variability which is often involved in the flow processes (Demuth and Hiltpold, 1993). Indirect measures may be obtained, for instance, from the patterns of water and solute discharge through tile drains in response to rain events. Most studies on the effect of tillage on drain water discharge and preferential flow have been focused on the two extremes of primary tillage, viz. moldboard plough and no-till management systems. The results of this research generally suggest that no-till increases the proportion of water transported in macropores (e.g. Harris et al., 1993; Lal et al., 1994). There are very limited data on the effect of secondary tillage on preferential flow.

Staining techniques as discussed by Flury and Flühler (1995) and applied e.g. by Ehlers (1975), Bouma et al. (1977), and Flury et al. (1994) do not, in a strict sense, quantify preferential flow. The techniques may, however, be used to visualize the primary flow pathways of water and solutes with high spatial resolution. Dye-tracing is, therefore, a valuable step towards an understanding of preferential flow and transport mechanisms in soil and towards the design of efficient schemes for soil sampling in solute transport studies. For tracing water, the applied dye should preferably be relatively mobile and distinctly visible.

The present work on dye-tracing field experiments investigates the effect of different tillage operations during 
seed bed preparation on depth distributions of preferential flow patterns appearing in the upper $1 \mathrm{~m}$ layer of a sandy loam soil.

\section{Materials and methods}

\section{SOIL AND TILLAGE}

The soil (Typic Agrudalf) in this study is at the university experimental farm, Højbakkegaard $20 \mathrm{~km}$ west of Copenhagen. The soil is developed on moraine deposits from the Weichsel Glacial Age. The structure is welldeveloped with vertically orientated earthworm channels of between 1 and $8 \mathrm{~mm}$ diameter penetrating into the Band C-horizons. Rough estimates of the number of channels were made on large lumps of soil taken from the profile. The largest numbers (about 8 per $100 \mathrm{~cm}^{2}$ horizontal cross section) were found in the $B_{1}$-horizon at about $50 \mathrm{~cm}$ depth. Common numbers found in the $B_{t}$-horizon between 40 and $80 \mathrm{~cm}$ depth were 2-5 channels per 100 $\mathrm{cm}^{2}$ horizontal cross section. There were coatings of clay indicating colloidal transport in several channels. Some (old) channels appearing right below the $A_{p}$-horizon (0-25 $\mathrm{cm}$ depth) were partly filled with soil materials in the upper $10 \mathrm{~cm}$. The number of channels increased abruptly below $35-40 \mathrm{~cm}$ depth, and decreased rapidly with depth below about $80 \mathrm{~cm}$. In the spring of 1994, a relatively well defined horizontal interface at about $20 \mathrm{~cm}$ depth marked the depth for the last ploughing in October 1993. Some profile characteristics are shown in Table 1.

Series of dye-tracer experiments were conducted in May, June, and October 1994 on 1.6 by $1.6 \mathrm{~m}$ plots laid out each time within a level field not more than $2.0 \mathrm{~m}$ from each other. One experiment was conducted within the same undisturbed area in July, 1996. The field was ploughed on 20 October, 1993 with incorporation of straw from the previous winter barley crop. Two seed bed harrowings in different directions were performed in April 1994 to a depth of $4-5 \mathrm{~cm}$, and some of the plots were also rotovated to a depth of either $5 \mathrm{~cm}$ or $15 \mathrm{~cm}$. The field was rolled and planted with Italian rye grass on 28 April, 1994. Plots to be used for tracer experiments in May 1994 were covered with waterproof tarpaulins immediately after seed bed preparation to minimize differences in evaporation. Traffic on the plots was avoided after sowing. In one plot, most of the topsoil was removed immediately before dye application so that the dye could be applied uniformly to a carefully prepared plane surface at $20 \mathrm{~cm}$ depth. Care was taken to avoid any disturbance of the soil structure below the new artificial surface.

Pilot investigations in May 1994 revealed that the soil at field capacity was always able to infiltrate $25 \mathrm{~mm}$ of water within one hour as applied by the sprinkling apparatus without noticeable surface ponding, whereas an intensity of $50 \mathrm{~mm} \mathrm{~h}^{-1}$ always resulted in local ponding on the surface. Saturated hydraulic conductivity, $\mathrm{K}_{\mathrm{s}}$, as determined for the vertical direction on $100 \mathrm{~cm}^{-3}$ laboratory samples taken at different locations within the field under study was log-normally distributed within each of four sampling depths (Gjettermann et al., 1997). For the 20-25 cm layer including the interface created during the last ploughing, they reported a geometric mean value for $K_{s}$ of 0.68 $\mu \mathrm{m} \mathrm{s}^{-1}$ and a geometric standard deviation of 2.8 ; for the $55-60 \mathrm{~cm}$ layer the geometric mean and standard deviation were 2.9 and $3.1 \mu \mathrm{m} \mathrm{s}^{-1}$, respectively. Outlines of the experimental conditions are given in Table 2.

\section{TRACER APPLICATION}

The dye tracer used for staining the flow paths of water was Brilliant Blue FCF. Tracer characteristics of Brilliant Blue FCF have recently been given by Flury \& Flühler $(1994,1995)$. The dye is anionic at $\mathrm{pH}>5.83$ and adsorbs relatively weakly on most soils.

The dye was applied in solution (concentration: $4 \mathrm{~g} \mathrm{l}^{-1}$ ) to the soil surface using an automatized sprinkling apparatus similar in principle to the ones described by Ghodrati et al. (1990a) and Flury et al. (1994). The device consists of a motor driven spray bar with nozzles aligned for one-dimen-

Table 1. Profile characteristics for the Højbakkegaard soil.

\begin{tabular}{|c|c|c|c|c|c|c|c|c|c|c|c|c|c|c|}
\hline \multirow[t]{2}{*}{ Horizon } & \multirow[t]{2}{*}{ Depth } & \multirow[t]{2}{*}{$\mathrm{pH}^{\dagger}$} & \multirow{2}{*}{$\begin{array}{l}\text { Org. } \\
\text { C }\end{array}$} & \multirow{2}{*}{$\begin{array}{l}\text { Texture } \\
0.2-2 \mathrm{~mm}\end{array}$} & \multirow{2}{*}{$20-200 \mu \mathrm{m}$} & \multirow[b]{2}{*}{$2-20 \mu \mathrm{m}$} & \multirow[b]{2}{*}{$<2 \mu \mathrm{m}$} & \multirow[t]{2}{*}{$\rho_{b}^{\ddagger}$} & \multicolumn{2}{|c|}{ Soil structure $\S$} & \multirow[b]{2}{*}{ Type } & \multicolumn{2}{|l|}{ Voids $\pi$} & \multirow[b]{2}{*}{ Abundane } \\
\hline & & & & & & & & & Grade & Size & & Type & Size & \\
\hline & $(\mathrm{cm})$ & & $(\%)$ & $(\%)$ & $(\%)$ & $(\%)$ & $(\%)$ & $\left(\mathrm{Mg} \mathrm{m}^{-3}\right)$ & & & & & & \\
\hline$A_{p}$ & $0-25$ & 6.3 & 1.4 & 23.6 & 34.9 & 23.3 & 16.8 & $1.39(0.10)$ & MO & ME & GR & $\mathbf{P}$ & $\mathbf{F}$ & $\mathbf{F}$ \\
\hline $\mathrm{E}$ & $25-40$ & 5.8 & 0.4 & 27.4 & 38.0 & 18.4 & 15.8 & $1.59(0.08)$ & MO & $\mathrm{ME}$ & $\mathrm{AB}$ & C & MC & $\mathrm{F}$ \\
\hline $\mathbf{B}_{\mathbf{t}}$ & $40-110$ & 6.2 & 0.2 & 23.0 & 35.0 & 18.6 & 23.2 & $1.63(0.08)$ & ST & ME & $\mathrm{AB}$ & C & MC & $\mathrm{C}$ \\
\hline $\mathrm{C}$ & $110+$ & 7.7 & - & 24.4 & 37.6 & 20.4 & 17.6 & - & MO & $\mathrm{CO}$ & $\mathrm{AB}$ & C & MC & $\mathrm{V}$ \\
\hline
\end{tabular}

$+0.01 \mathrm{M} \mathrm{CaCl}$.

I Determined in April 1994 from $15100 \mathrm{~cm}^{3}$ soil samples taken about in the middle of the indicated soil layer. Standard deviation in brackets.

$\$$ According to Food and Agriculture Organization, 1990. Grade: VW=Very Weak, MO=Moderate, ST=Strong. Size: $M E=M e d i u m, C O=C o a r s e, F M=F i n e$ and Medium. Type: $\mathbf{G R}=$ Granular, $\mathbf{A B}=$ Angular Blocky .

1 According to Food and Agriculture Organization, 1990. Type: $\mathrm{C}=\mathrm{Channels}$ (mainly vertically orientated, continuous earthworm channels), $\mathrm{P}=\mathrm{Planes}$ (mainly randomly orientated and discontinuous), $\mathrm{I}=\mathrm{Interstitials}$ (textural voids), Size: $\mathrm{V}=$ Very Fine $(<0.5 \mathrm{~mm}), \mathrm{F}=\mathrm{Fine}(0.5-2 \mathrm{~mm}), \mathrm{M}=\mathrm{Medium}(2-5 \mathrm{~mm}), \mathrm{C}=\mathrm{Coarse}(5-20 \mathrm{~mm})$, $\mathrm{MC}=$ Medium and Coarse. Abundance: $\mathrm{F}=\mathrm{Few}, \mathrm{C}=\mathrm{Common}, \mathrm{V}=$ Very few. 
Table 2. Overview of experimental treatments and conditions.

\begin{tabular}{|c|c|c|c|c|c|c|c|}
\hline \multirow{2}{*}{$\begin{array}{l}\text { Identi- } \\
\text { fication }\end{array}$} & \multirow{2}{*}{ Treatment $^{\dagger}$} & \multirow{2}{*}{$\begin{array}{l}\text { Cross } \\
\text { sections }\end{array}$} & \multicolumn{5}{|c|}{ Bulk density, $\rho_{\mathrm{b}}$, and soil moisture content, $\theta$} \\
\hline & & & Depth & $\rho_{\mathrm{b}}$ & $\theta$ & Depth & $\theta$ \\
\hline & & & $(\mathrm{cm})$ & $\left(\mathrm{Mg} \mathrm{m}^{-3}\right)$ & $\left(\mathrm{m}^{3} \mathrm{~m}^{-3}\right)$ & $(\mathrm{cm})$ & $\left(\mathrm{m}^{3} \mathrm{~m}^{-3}\right)$ \\
\hline 17.05 .94 & Rot. $15 \mathrm{~cm}$ & Vertical & $5-10$ & $1.28(0.12)$ & 0.174 & $25-35$ & 0.234 \\
\hline 18.05 .94 & Rot. $5 \mathrm{~cm}$ & Vertical & $0-6$ & $1.21(0.09)$ & 0.136 & $25-35$ & 0.255 \\
\hline 19.05 .94 & Convent. & Vertical & $0-2$ & - & $0.119 \ddagger$ & $25-35$ & 0.251 \\
\hline 20.05 .94 & T. removed & Vertical & - & - & - & $25-35$ & 0.261 \\
\hline 31.05 .94 & Convent. & Vertical & $5-10)$ & $1.62(0.14)$ & 0.311 & $25-35$ & 0.288 \\
\hline 01.06 .94 & Convent. & Horizontal" & $5-10]$ & & 0.289 & $25-35$ & 0.295 \\
\hline 02.06 .94 & Rot. $15 \mathrm{~cm}$ & Vertical & $5-10$ & $1.30(0.11)$ & 0.280 & $25-35$ & 0.269 \\
\hline 03.06 .94 & Rot. $5 \mathrm{~cm}$ & Vertical & $0-6$ & $1.27(0.07)$ & 0.297 & $25-35$ & 0.273 \\
\hline 27.10 .94 & Convent. & Vertical & $5-10$ & $1.37(0.09)$ & 0.228 & $25-35$ & 0.229 \\
\hline 28.10 .94 & Rot. $15 \mathrm{~cm}$ & Vertical & $5-10$ & $1.25(0.11)$ & 0.201 & $25-35$ & 0.230 \\
\hline 07.07 .96 & Convent. & Vertical & $5-10$ & $1.67(0.07)$ & 0.281 & $25-35$ & 0.296 \\
\hline
\end{tabular}

† Convent.: conventional soil tillage corresponding to two or three seed bed harrowings in different directions to a depth of $4-5 \mathrm{~cm}$, rolling and sowing (grass). Rot.: Rotovation to 15 , respectively $5 \mathrm{~cm}$ as supplement to the conventional treatment right after harrowing. $T$. removed: Topsoil removed before dye application.

$\$$ Calculated by assuming the same dry bulk density as in rotovated plots, $0-6 \mathrm{~cm}$

$\$$ Date when the excavation proces was initiated and the day after dye application. Identifies each plot / experiment.

I Horizontal to $80 \mathrm{~cm}$ depth, vertical below $80 \mathrm{~cm}$.

sional application of the solution directly under the bar and a suction pump connected to tanks containing the dye solution. The impact energy of the sprinkling drops produced was small. $25 \mathrm{~mm}$ of dye solution was applied within one hour in all experiments. This was achieved by a timer switching the device on and off at equal time intervals of 2 minutes. The device was designed to ensure a controlled and spatially uniform distribution of dye tracer at the soil surface. The uniformity of application depends on the nozzle distance above the soil surface and on the nozzle pressure. The best combination of these conditions was found in the laboratory. For an inner area of 110 by $110 \mathrm{~cm}$, it was possible to achieve a coefficient of variation of the amount of applied solution of 5-6\% in the direction perpendicular to the travel direction, and $2-3 \%$ in the travel direction when measuring the amount of irrigation water in 10 by 10 $\mathrm{cm}$ trajectories placed side by side. In the field, wind drift was reduced by a wooden frame surrounding the treated area, and all vertical soil profiles were made parallel to the travel direction of the bar. All above-grourd plant materials, if any, were removed before dye application.

\section{SAMPLING}

The plots were excavated one or two days after dye application to a depth of about $160 \mathrm{~cm}$. An excavator was used to dig a trench in front of the treated area and to remove all loosened soil from the bottom of the excavation. All soil below the treated area was loosened with hand spades and horizontal or vertical cross sections were prepared for detailed description. The cross sections were trimmed with a trowel and a knife and, in the case of horizontal cross sections, also with a soft brush. Special care was taken to remove all deposits of dye coming from the excavation process. Most plots were excavated systematically in 11 vertical cross sections separated $10 \mathrm{~cm}$ from each other. One plot (01.06.94) was excavated horizontally to $80 \mathrm{~cm}$ depth, and vertically below $80 \mathrm{~cm}$ depth. Flow patterns and relevant structural features appearing on the cross sections or in the soil layer between sections were described and photographed. A 100 by $100 \mathrm{~cm}$ square metal frame was placed on all cross sections before taking photos for image analysis. Soil samples were taken before dye application and during the excavation process to determine soil bulk density and moisture content.

\section{IMAGE ANALYSIS}

On the photographs all stained dye patterns appearing within the metal frame were transferred manually with a fine black pen to transparent plastic sheets. The only distinction made in this process was whether blue dye was visible or not at the different parts of the photo. A representation of the metal frame (approximate size: 10 by $10 \mathrm{~cm}$ ) was transferred as well. All transfers were made or controlled by one person. 
The new representations of the flow patterns were digitized with a resolution of $300 \mathrm{dpi}$ (dots per inch) by either an Agfa Arcus or a Hewlet Packard scanner. The resulting binary representations were displayed on a datascreen on which were marked the four corners of the metal frame with known coordinates. The computer program then made a projective geometric transformation of that part of the image inside the frame into a quadratic representation with 464 true horizontal rows and 464 true vertical columns. For each row, the computer counted the number of pixels which were turned on (representing a stained area), and the number of transitions from pixels which were turned off to pixels which were turned on. Average values were calculated for each profile depth increment of 8 rows $(1.7 \mathrm{~cm})$ to reduce the random error. From these data, average dye coverage (DC, \%) and average number of stained flowpathways (NP) were calculated as a function of profile depth.

\section{Results}

In the uppermost part of the vertical profiles, there was always a completely stained soil layer (Figs. 1 and 2). Below this layer, the flow pattern became more heterogeneous, this effect being most pronounced in conventionally tilled plots. Flow patterns in the subsoil below $35-40 \mathrm{~cm}$ depth were dominated completely by dye deposited at the surface of vertically orientated earthworm channels. It was often possible to follow these channels over long distances in the subsoil by careful excavation with a knife. However, only sections of the stained channels appeared on vertical cross sections. Larger stained areas were found at the ends of some of the channels indicating the existence of internal catchments (e.g. Fig. 2a). Dye was found below $100 \mathrm{~cm}$ depth on 26 out of the 33 vertical cross sections made in conventionally tilled plots in May and early June 1994.

Any close relationship between the amount of dye deposited in the subsoil at the surface of earthworm chan- nels and the area and intensity of the blue flow patterns can hardly be expected because the dye was concentrated within very small soil volumes and because of geometrical and optical factors (e.g. shadows cast over parts of the stained channel surfaces). The dye application caused no noticeable ponding at the soil surface except in the experiment with topsoil removed (20.05.94).

\section{ROTOVATION}

Average values for NP and DC as a function of depth are shown for the plots excavated in vertical cross sections in Fig. 3. This figure and the images shown in Figs. 1 and 2 clearly suggest an effect of rotovation on the penetration of dye patterns. The average number of stained pathways below $25 \mathrm{~cm}$ depth, $\mathrm{NP}^{\prime}{ }_{25}$, and the average degree of dye coverage above $25 \mathrm{~cm}$ depth, $\mathrm{DC}_{25}^{\prime}$, were derived for each of the 11 cross sections made within each plot. The Shapiro-Wilk statistic for Normality (Shapiro \& Wilk, 1965) was calculated for both variables, except for $N^{2}{ }^{\prime} 25$ in plots without dye penetration into the subsoil (17.05.94 and 02.06.94). The statistic did not, in any plot, lead to a rejection of the hypothesis that the observed values represented normal distributions $(\mathrm{P}>0.05)$. Within-plot average values and standard deviations for $\mathrm{NP}_{25}$ and $\mathrm{DC}_{25}$ are shown in Table 3. There were no examples of dye penetration below $25 \mathrm{~cm}$ in May or in June after deep rotovation, whereas $\mathrm{NP}_{25}$, in conventionally tilled plots at approximately the same dates, was significantly different from zero $(\mathrm{P}<0.001)$. In May, when the uppermost soil layers were relatively dry (Table 2 ), there were only a few examples of dye penetrating the upper part of the subsoil in the superficially rotovated plot, and the difference between values of $\mathrm{NP}_{25}$ for the superficially rotovated and the conventionally tilled plots was strongly significant $(P<$ 0.001 ). $\mathrm{NP}_{25}$ was also smaller in a superficially rotovated plot than in a conventionally tilled plot in June, when the moisture content of the whole profiles, including the

Table 3. Average number of stained pathways in the $25-100 \mathrm{~cm}$ subsoil layer, $\mathrm{NP}_{25}$, and average degree of dye coverage above $25 \mathrm{~cm}$ soil depth, $\mathrm{DC}_{25}$ in differently treated plots. Standard deviations in brackets $(\mathrm{n}=11)$. ns, ", "**, and ${ }^{* * *}$ : difference between conventional and rotovated plots at the time of excavation either non-significant or significant at the 95 , 99 or $99.9 \%$ level, respectively, according to t-test.

\section{Treatment}

\begin{tabular}{|c|c|c|c|c|c|c|c|c|c|c|}
\hline \multirow[t]{2}{*}{$\begin{array}{l}\text { Time of } \\
\text { excavation }\end{array}$} & \multicolumn{2}{|c|}{ Conventional } & \multicolumn{2}{|c|}{$\begin{array}{l}\text { Rotovated } \\
5 \mathrm{~cm}\end{array}$} & \multicolumn{2}{|c|}{$\begin{array}{c}\text { Rotovated } \\
15 \mathrm{~cm}\end{array}$} & \multicolumn{4}{|c|}{$\begin{array}{l}\text { Topsoil } \\
\text { removed }\end{array}$} \\
\hline & $\mathrm{NP}_{25}$ & $\mathrm{DC}_{25}$ & $\mathrm{NP}_{25}$ & $\mathrm{DC}_{25}$ & $\mathrm{NP}_{25}$ & $\mathrm{DC}_{25}$ & $\mathbf{N P}_{25}$ & & $\mathrm{DC}$ & \\
\hline Mid May 1994 & $2.4(1.0)$ & $46(5)$ & $0.0^{* * * *}(0.0)$ & $34^{* * *}(4)$ & $0.0^{* * *}(0.0)$ & $48^{\mathrm{ns}}(4)$ & 8.6 & (2.7) & 66 & (9) \\
\hline Early June 1994 & $2.5(2.2)$ & $40(10)$ & $0.7^{*}(0.7)$ & $39^{\text {ns }}(5)$ & $0.0^{* * * *}(0.0)$ & $39^{\mathrm{ns}}(8)$ & - & - & - & - \\
\hline Late October 1994 & $2.6(1.3)$ & $44(8)$ & $-\quad-$ & $-\quad-$ & $1.0^{* * *}(0.8)$ & $44^{\mathrm{ns}}(7)$ & - & - & - & - \\
\hline July 1996 & $3.7(0.7)$ & $61(5)$ & - & - & $-\quad-$ & - & - & - & - & - \\
\hline
\end{tabular}

$+25-100 \mathrm{~cm}$ below the original soil surface

t $20-25 \mathrm{~cm}$ below the original soil surface 


\section{Conventional}
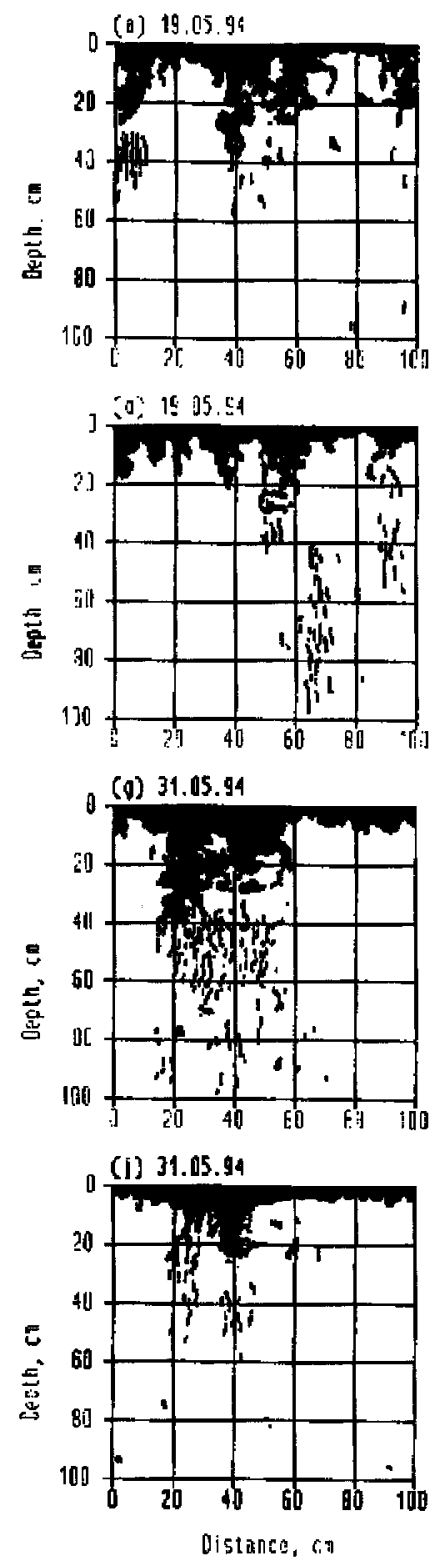

Rot., $5 \mathrm{~cm}$

(b) 18 05 14

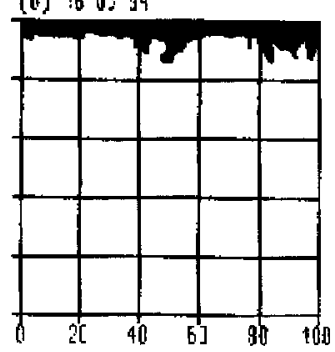

(e) :日 0: 34

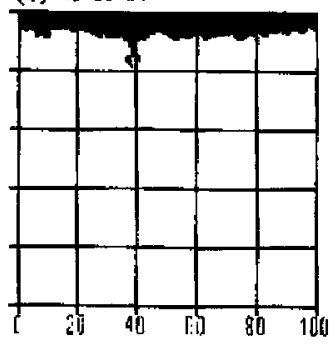

(II) 83.06 .94

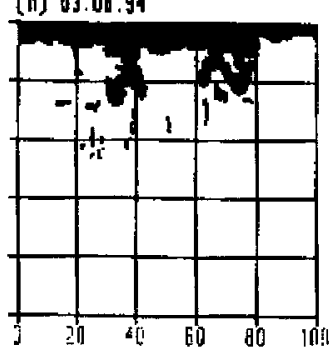

(k) 03.05.94

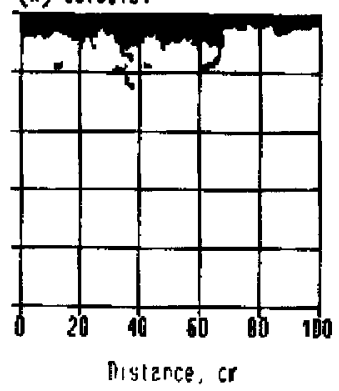

Rot., $15 \mathrm{~cm}$

(c) $17,05.94$

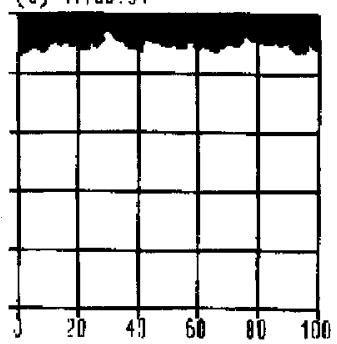

(i) 17.05 .94

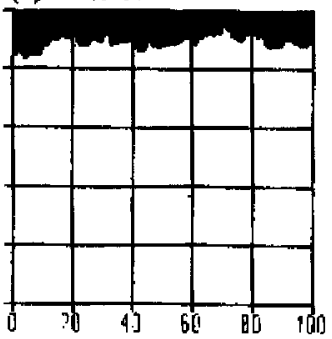

(1) 02.05 .94

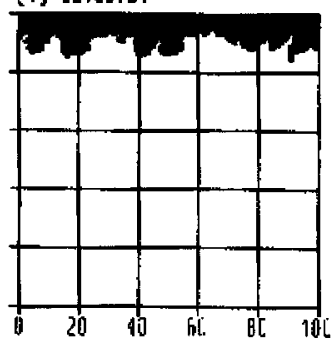

(1) 02.46.91

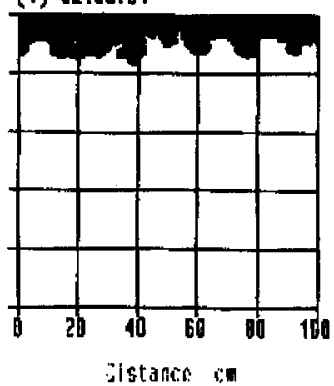

Fig. 1. Digitized and geometrically corrected flow patterns from vertical cross sections made in May or early 7 une 1994 in $(a, d, g, j)$; conventionally tilled plots, $(b, e, h, k)$; plots rotovated to $5 \mathrm{~cm}$ depth, and $(c, f, i, l) ;$ plots rotovated to $15 \mathrm{~cm}$ depth.

uppermost few $\mathrm{cm}$, was close to the field capacity after rewetting $(\mathrm{P}<0.05)$, although the number of stained channels in the subsoil of the rotovated plot was increased significantly $(\mathrm{P}<0.001)$ compared with the situation in May. $\mathrm{DC}_{25}$ was significantly smaller in the superficially rotovated plot than in the conventionally tilled plot in May $(P<0.001)$ but not in June.

$\mathrm{NP}_{25}$ was smaller in a deeply rotovated plot than in a conventionally tilled plot also in late October 1994, 6 months after seed bed preparation $(P<0.01$, cf. Table 3$)$. The depth functions for DC were obviously different at that time, DC being higher above $15 \mathrm{~cm}$ depth and lower below $15 \mathrm{~cm}$ depth for the deeply rotovated plot compared with the conventionally tilled plot (Figs. 2 and 3).

FLOW PATTERNS ON VERTICAL PROFILES AS AFFECTED BY SOIL STRUCTURE IN THE 20-40 CM SOIL LAYER

In conventionally tilled plots the patterns often changed abruptly in shape at the interface created during the last ploughing operation at about $20 \mathrm{~cm}$ or at $30-35 \mathrm{~cm}$ depth (Figs. 1 and 2). Local minima for NP and DC were found at about $30 \mathrm{~cm}$ depth, both in 1994 (Fig. 3) and in 1996. 
Conventional
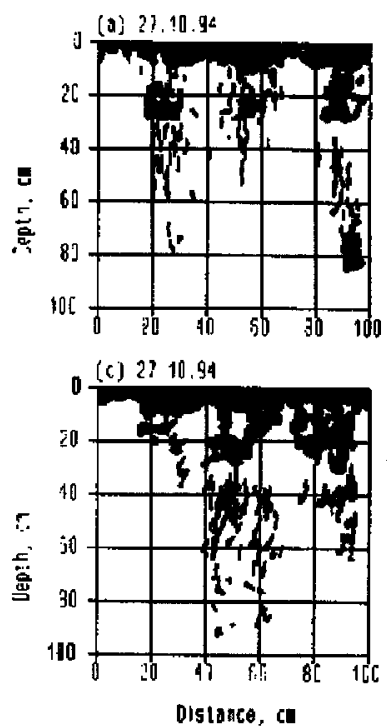

Rot., $15 \mathrm{~cm}$

(j) 281094

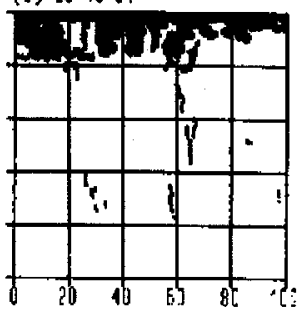

[d] ?3.10.94

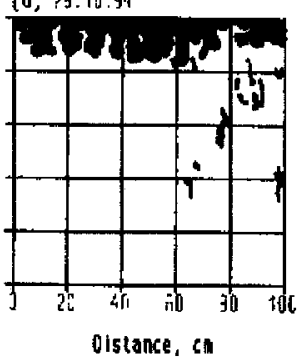

Fig. 2. Digitized flow patterns from vertical cross sections made in October 1994 in $(a, c)$ : conventionally tilled plots and $(b, d):$ plots rotovated to $15 \mathrm{~cm}$ depth.

Thus, conditions creating local minima for NP and DC at about $30 \mathrm{~cm}$ depth still existed in the third year grass field. The fact that local maximum values for NP were found at about $40 \mathrm{~cm}$ depth corresponds with the profile description that the number of vertically orientated open earthworm channels are larger for the $\mathrm{B}_{\mathfrak{t}}$-horizon than for the A- and E-horizons.

Other indications of the modifications of flow patterns in the $20-40 \mathrm{~cm}$ soil layer were obtained from the plot with topsoil removed (20.05.94). Very distinct horizontal structures in the flow patterns at 5-15 cm depth $(25-35 \mathrm{~cm}$ below the original soil surface) indicate soil layering with abrupt changes in hydraulic properties (Fig. 4). These changes may be related to soil compaction or to earlier tillage operations. The upper level boundary receiving an even amount of dye solution was located from 0 to about $4 \mathrm{~cm}$ above the interface made during the last ploughing operation. The number of stained pathways increased dramatically and abruptly below $10-15 \mathrm{~cm}$ depth (Fig. $4 \mathrm{a}-\mathrm{d}$ ). It seems most likely that the conditions for this change in the flow patterns were created during an earlier ploughing. Later, the structure along this deep interface may have been modified, for instance through biological activity. Only horizontal transport at the interface can explain the extensive activation of channels appearing very often exactly at that depth. When looking at moist, more or less smeared vertical profiles in the field, it was generally impossible to see any horizontal channels, with the exception of a few larger ones. However, when breaking dried samples in the laboratory, the number of horizontally orientated root channels of diameter $<0.5 \mathrm{~mm}$ was generally much larger just above the interface than just below. It is concluded that the deep interface at $30-35 \mathrm{~cm}$ depth had a dominating effect on the appearance of flow patterns in experiment 20.05.94 with removed topsoil. The extent to which this interface affected flow patterns in intact soil profiles is less obvious.

\section{FLOW PATTERNS ON HORIZONTAL CROSS SECTIONS}

Digitized and geometrically corrected images of flow patterns on horizontal, 100 by $100 \mathrm{~cm}$ cross-sections made in a conventionally tilled plot in May are shown in Fig. 5. At $8 \mathrm{~cm}$ depth, the patterns were strongly orientated (Fig. $5 \mathrm{a}$, much more evident on the original colour reprints). The direction indicated by the patterns corresponds closely to the direction of the last seed bed harrowing. The degree

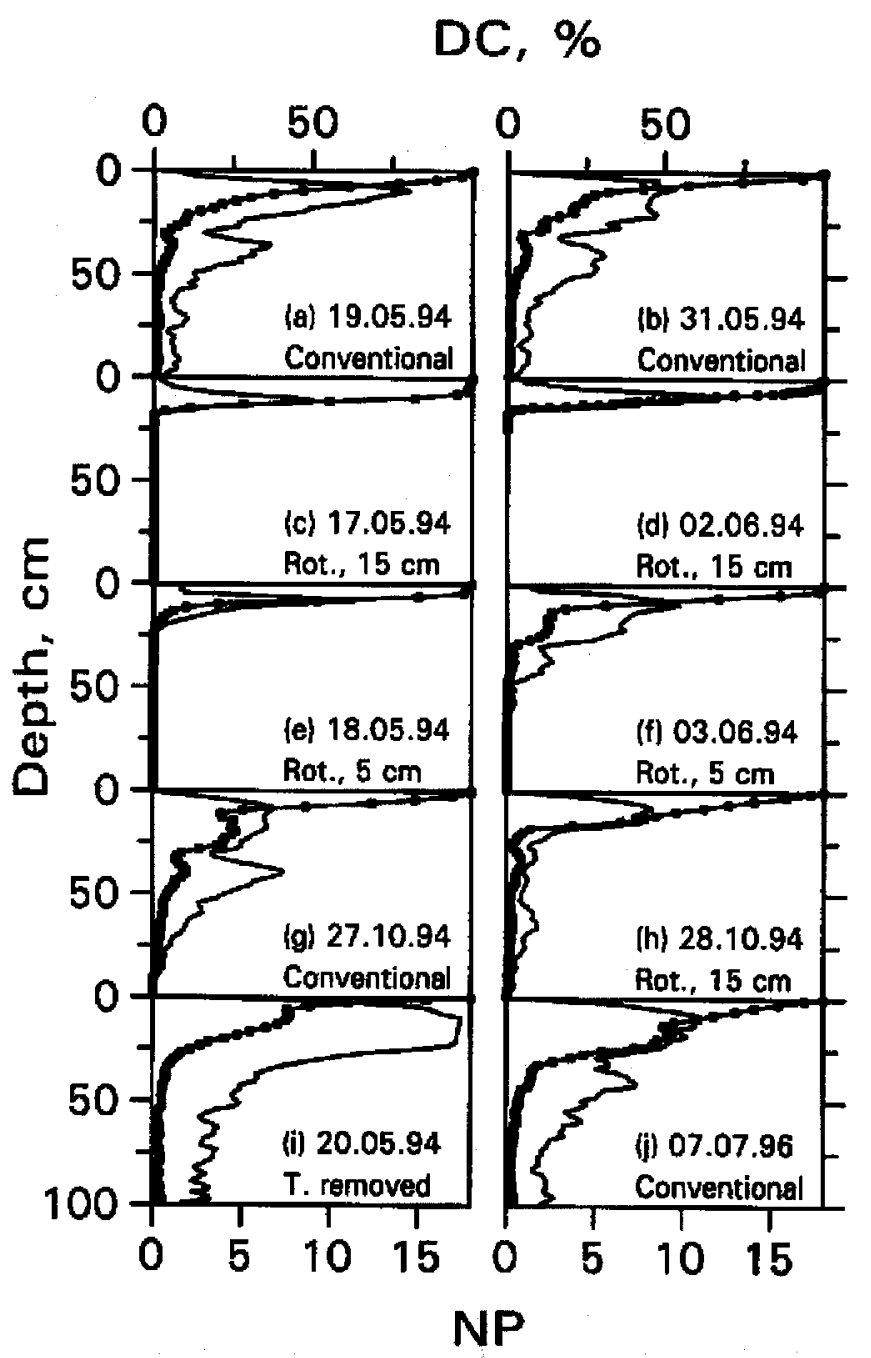

Fig. 3. Depth profiles of the average number of flom pathways, NP (- $\longrightarrow$ and the average degree of dye coverage, DC (-1-) in single plots. For (i): depth indications refer to the uncovered artificial soil surface. 

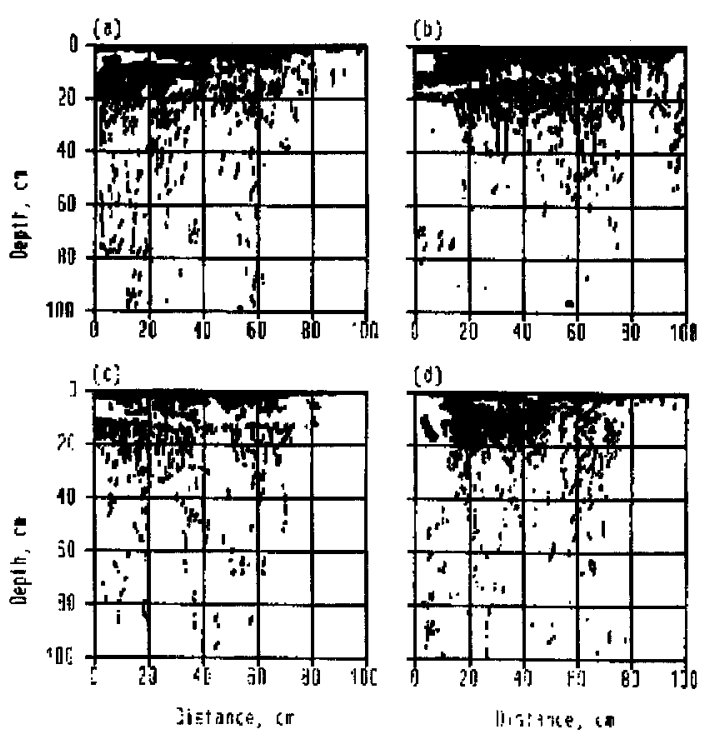

Fig. 4. Digitized flow patterns from vertical cross sections in plot with topsoil removed (20.05.94).

of dye coverage is much less at $15 \mathrm{~cm}$ depth and the effect of seed bed preparation is no longer obvious (Fig. 5b). The flow patterns tend to be more concentrated in cracks, probably between structural units left unbroken by the plough. The direction of ploughing in 1993 was parallel to the second axis. From about $15 \mathrm{~cm}$ to the ploughing depth, there were areas with buried, partly decomposited crop residues (straw) covering up to about $5 \%$ of the cross section. The dye patterns reaching these areas from above tended to spread both horizontally and vertically along the residues. There was considerable earth worm activity, especially in the areas with straw but its influence on the continuity of preferential flow pathways is not clear.

Although it was easy to identify the bottom of the furrow layer at about $22 \mathrm{~cm}$ depth, either as a plane of weakness or from its tendency to stop many flow patterns from above, it was difficult to uncover the bottom as a whole. The horizontal cross section shown in Fig. 5c was made as close to the bottom as possible. Also, at this depth, the shapes of the dye patterns indicated that flow took place mainly in cracks. Many of the stained cracks were running parallel to each other. Generally, these cracks could be traced below the ploughing depth; it is assumed that they were created originally by the shearing action of the plough.

Clearly the patterns change from 22 to $32 \mathrm{~cm}$ depth (Figs. 5c and 5d, respectively). There were no stained cracks at $32 \mathrm{~cm}$ depth. Most of the patterns were more or less round, small spots. Due to some inevitable smearing of the moist surface of the cross sections, it was seldom possible to see any central orifice in these dyed spots. However, by breaking dried soil samples, most of the flow pathways in this layer proved to be channels less than $1 \mathrm{~mm}$ in diameter (mostly root channels), in addition to a number of larger, stained earthworm channels. In some cases, the small dyed spots lay very close to each other, thereby comprising larger stained unities. Patterns on horizontal cross sections made below $40 \mathrm{~cm}$ depth appeared as spots (up to about $1 \mathrm{~cm}$ in diameter) enclosing central earthworm channels of diameters in the range of 1-8 $\mathrm{mm}$.

\section{Discussion}

The fact that many channels below $30-35 \mathrm{~cm}$ can be fed by relatively few pathways above this depth means that these uppermost pathways have to be efficient. The local minimum for NP at about $30 \mathrm{~cm}$ depth suggests a shift from flow mainly in relatively large cracks to flow taking place mainly in channels. Local minima for NP and DC at about $30 \mathrm{~cm}$ depth were also reported by Gjettermann et al. (1997) for dye tracing experiments conducted in conventionally tilled plots in 1994 and 1995 at the same field area but only for large dye application rates $(50,25$, and $12.5 \mathrm{~mm}$ $\left.\mathrm{h}^{-1}\right)$, rather than for low rates $\left(6.3\right.$ and $\left.3.1 \mathrm{~mm} \mathrm{~h}^{-1}\right)$. They reported that, for the application intensity of $3.1 \mathrm{~mm} \mathrm{~h}^{-1}$, all stained earthworm channels penetrating to more than 90 $\mathrm{cm}$ depth could be traced all the way to the soil surface. The most extensive activation of channel flow ever found in the present work was observed in experiment 20.05.94 with topsoil removed and ponding $20 \mathrm{~cm}$ below the original soil surface. The activation of channel flow in the transition zone between tilled and untilled soil may be supported by a pressure build-up in the soil water in this zone.

The average number of activated flow channels in the depth interval $25-100 \mathrm{~cm}, \mathrm{NP}_{25}$, was larger in experiment 07.07.96 than in experiment 19.05.94 $(\mathrm{P}<0.01)$ whereas the difference between experiment 07.07 .96 and 31.05 .94 was
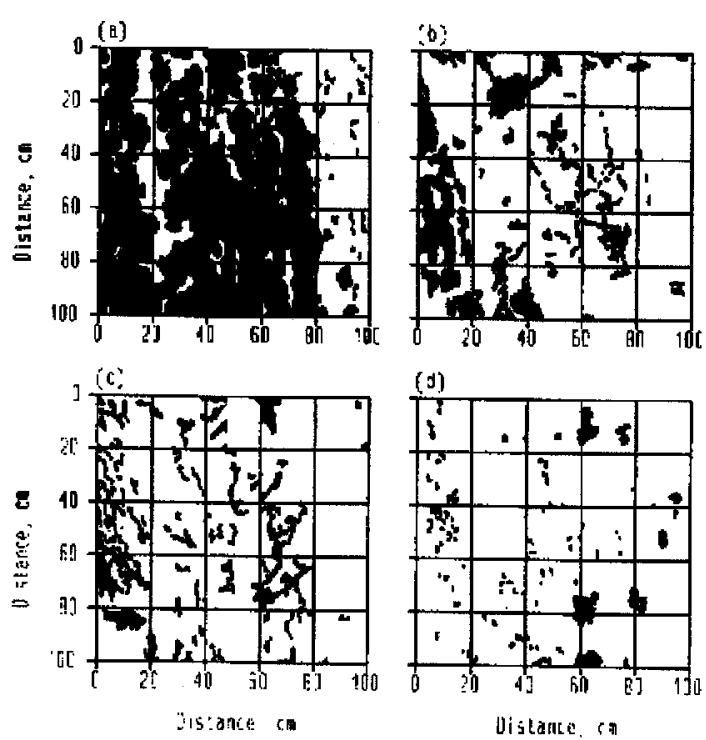

Fig. 5. Digitized flow patterns from horizontal cross sections in a conventionally tilled plot (01.06.94) made in (a): $8 \mathrm{~cm}$ depth, (b): $15 \mathrm{~cm}$ depth, (c): $22 \mathrm{~cm}$ depth, and (d): $32 \mathrm{~cm}$ depth. 
non-significant (Table 3). The average degree of dye coverage above $25 \mathrm{~cm}$ depth, $\mathrm{DC}_{25}$, was significantly larger in July 1996 than in the early experiments in $1994(\mathrm{P}<0.001)$. The flow patterns in July 1996 may have been affected by a large number of living roots present in the topsoil at that time. Nevertheless, the uppermost completely stained soil layer was typically less than $1 \mathrm{~cm}$ thick in July 1996 which is less than the typical thickness $(2-4 \mathrm{~cm})$ found in the conventionally tilled plots in 1994.

Ghodrati et al. (1990b) investigated the effects on flow patterns in the root zone of disturbing the soil structure in the upper $30-40 \mathrm{~cm}$ with a trencher. They worked with a sandy soil without visible macropores and the anionic dye tracer Acid-Red 1. The disturbance altered the flow patterns dramatically. Both the tendency of finger formation just below the treated soil layer and the percentage of dye coverage in the subsoil below $70-80 \mathrm{~cm}$ were increased. In the present study, however, soil disturbance by rotovation reduced the depth of penetration of dye patterns. The different results may be explained by differences in soil type and soil treatment, a homogenizing effect of soil disturbance on soil structure being more likely in the present study. Furthermore, Ghodraty et al. (1990b) applied 100 $\mathrm{mm}$ of irrigation water to their plots compared with 25 $\mathrm{mm}$ in the present study.

\section{Conclusions}

Based on field dye tracer experiments on the $1 \mathrm{~m}$ scale conducted on a structured sandy loam soil, it is concluded:

1. Preferential flow was a prevailing phenomenon in the topsoil and in the subsoil of conventionally tilled plots.

2. Preferential flow in terms of channel flow was generated at structural interfaces located in the $20-40 \mathrm{~cm}$ depth interval.

3. Rotovation as a supplement to conventional seed bed prepatation significantly reduced the penetration of stained flow patterns into the subsoil.

\section{References}

Beven, K. and Germann, P. 1982. Macropores and water flow in soils. Wat. Resour. Res., 18: 1311-1325.

Bouma, J., Jongerius, A., Boersma, O., Jager, A. and Schoonderbeek, D. 1977. The function of different types of macropores during saturated flow through four swelling soil horizons. Soil Sci. Soc Am. F., 41: 945-950.

Bouma, J. 1991. Influence of soil macroporosity on environmental quality. Adv. Agron., 46: 1-37.

Demuth, N. and Hiltpold, A. 1993. 'Preferential flow': Eine Übersicht über den heutigen Kenntnisstand. Z. Pflanzenernähr. Bodenk., 156: 479-484.

Ehlers, W. 1975. Observations on earthworm channels and infiltration on tilled and untilled loess soil. Soil Sci., 119: 242-249.
Food and Agriculture Organization. 1990. Guidelines for Soil Description. 3rd ed. Food and Agriculture Organization of the United Nations, Rome. 70 pp.

Flury, M. 1996. Experimental evidence of transport of pesticides through field soils.-A review. 7. Environ. Qual., 25: 25-45.

Flury, M. and Flühler, H. 1995. Tracer characteristics of Brilliant Blue FCF. Soil Sci. Soc. Am. 7., 59: 22-27.

Flury, M. and Flühler, H. 1994. Brilliant Blue FCF as a dye tracer for solute transport studies-A toxicological overview. 7. Environ. Qual., 23: 1108-1112.

Flury, M., Flühler, H., Jury, W.A. and Leuenberger, J. 1994. Susceptibility of soils to preferential flow of water: A field study. Wat. Resour. Res., 30: 1945-1954.

Ghodrati, M., Frederick, F.E. and Jury, W.A. 1990a. Automated spray system for application of solutes to small field plots. Soil Sci. Soc. Am. 7., 54: 287-290.

Ghodrati, M. and Jury, W.A. 1990b. A field study using dyes to characterize preferential flow of water. Soil Sci. Soc. Am. 7., 54: 1558-1563.

Gjettermann, B., Nielsen, K.L., Petersen, C.T., Jensen, H.E. and S. Hansen. 1997. Preferential flow in sandy loam soils as affected by irrigation intensity. Soil Technology, 11:139-152.

Hall, J.K. and Mumma, R.O. 1994. Dicamba mobility in conventionally tilled and non-tilled soil. Soil Tillage Res., 30: 3-17.

Hall, J.K., Murray, M.R. and Hartwig, N.L. 1989. Herbicide leaching and distribution in tilled and untilled soil. 7. Environ. Qual., 18: 439-445.

Harris, G.L., Howse, K.R. and Pepper, T.J. 1993. Effects of moling on soil-water and runoff from a drained clay soil. Agric. Wat. Manag., 23: 161-180.

Horton, R., Allmaras, R.R. and Cruse, R.M. 1989. Tillage and compactive effects on soil hydraulic properties and water flow. In: W.E. Larson, G.R. Blake, R.R. Allmaras, W.B. Voorhees and S.C. Gupta (Editors), Mechanics and related processes in structured agricultural soils. Kluwer Acad. Publ., Dordrecth, pp. 187-203.

Isensee, A.R., Nash, R.G. and Helling, C.S. 1990. Effect of conventional vs. no-tillage on pesticide leaching to shallow groundwater. 7. Environ. Qual., 19: 434-440.

Jury, W.A. and Flühler, H. 1992. Transport of chemicals through soil: Mechanisms, models, and field applications. Adv. Agron., 47: 141-201.

Kladivko, E.J., Van Scoyoc, G.E., Monke, E.J. Oates, K.M. and Pask, W. 1991. Pesticide and nutrient movement into subsurface tile drains on a silty loam soil in Indiana. 7. Environ. Qual., 20: 264-270.

Lal, R., Logan, T.J., Eckert, D.J., Dick, W.A. and Shipitalo, M.J. 1994. Conservation tillage in the corn belt of the United States. In: M.R. Carter (Editor), Conservation tillage in temperate agroecosystems. Lewis Publishers, London, pp. 73-114.

Shapiro, S.S. and Wilk, M.B. 1965: An analysis of variance test for normality (complete samples). Biometrika, 52: 591-611.

Staricka, J.A., Allmaras, R.R. and Nelson, W.W. 1991. Spatial variation of crop residue incorporated by tillage. Soil Sci. Soc. Am. F., 55: 1668-1674. 